\title{
Novos jornalistas literários: métodos, técnicas e experimentações
}

\author{
New literary journalists: methods, techniques and experimentations
}

\section{Los nuevos periodistas literarios: métodos, técnicas y esperimentaciones}

\author{
Eduardo Ritter ${ }^{l}$
}

\begin{abstract}
Resumo
Nos anos 1960 surgiu nos Estados Unidos um grupo de jornalistas que adotaram um estilo que ficou conhecido como New Journalism por utilizar no texto jornalísticos elementos da literatura e da narrativa ficcional. Inspirados no glamour da literatura, eles encontraram no jornalismo uma forma de se tornar escritor. Quase 50 anos depois, Boynton (2005), também nos Estados Unidos, apresenta a proposta de inverter os papeis: se valer da literatura para se fazer jornalismo. É o repórter colocando o jornalismo em primeiro plano. Para tanto, Boynton entrevistou diversos novos jornalistas literários para revelar os seus métodos e técnicas. Baseado nessas entrevistas, o presente artigo tem o objetivo de analisar esse cenário que surge em uma sociedade totalmente informatizada. Para tanto, utiliza-se a pesquisa bibliográfica, tendo como metodologia a perspectiva do ensaio como forma, de Theodor Adorno. Ao contrário do que é esperado e imaginado pelos tecnófilos do jornalismo, os métodos e técnicas utilizados pelos jornalistas literários contemporâneos seguem priorizando o contato pessoal e a entrevista em profundidade.
\end{abstract}

Palavras-Chave: Jornalismo. Literatura. Narrativa. História. Metodologia.

\begin{abstract}
In the 1960s emerged in the United States a group of journalists who have adopted a style that became known as New Journalism because they used elements of literature and fictional narrative in the text journalistic. Inspired by the glamor of literature, they found a way in journalism to become a writer. Almost 50 years later, Boynton (2005), also in the United States, presents the proposal to reverse the roles: make use of literature to journalism. Is the reporter putting journalism in the foreground. Therefore, Boynton interviewed several new literary journalists to reveal their methods and techniques. Based on these interviews, this article aims to analyze this scenario that arises in a fully computerized society. For this, it uses bibliographic research, with the methodology the perspective of the essay as a way of Theodor Adorno. Contrary to what is expected and imagined by journalism technophiles, the methods and techniques used by contemporary literary journalists follow prioritizing personal contact and in-depth interview.
\end{abstract}

Keywords: Journalism. Literature. Narrative. History. Methodology.

\section{Resumen}

En la década de 1960 se puso de manifiesto en los Estados Unidos un grupo de periodistas que han adoptado un estilo que llegó a conocerse como nuevo periodismo de utilizar los elementos de texto periodísticos de la literatura y la narrativa de ficción. Inspirado en el glamour de la literatura, encontraron una forma de periodismo para convertirse en escritor. Casi 50 años más tarde, Boynton

\footnotetext{
${ }^{1}$ Professor adjunto da Universidade Federal de Santa Maria (UFSM). Doutor e mestre em Comunicação Social pela Pontifícia Universidade Católica do Rio Grande do Sul (PUCRS) com estágio doutoral na New York University (NYU). Jornalista graduado pela Unijuí-RS. E-mail: rittergaucho@ hotmail.com.
}

Comun. \& Inf., Goiânia, GO, v. 21, n. 1, p. 20-36, jan./mai. 2018 
(2005), también en los Estados Unidos presenta la propuesta de invertir los papeles: hacer uso de la literatura al periodismo. Es el reportero poner el periodismo en el primer plano. Por lo tanto, Boynton entrevistó a varios nuevos periodistas literarios para revelar sus métodos y técnicas. Sobre la base de estas entrevistas, este artículo tiene como objetivo analizar este escenario que surge en una sociedad totalmente informatizado. Para esto, se utiliza la literatura, con la metodología de la perspectiva de la prueba como una forma de Theodor Adorno. Al contrario de lo que se espera y imaginada por tecnófilos periodismo, los métodos y técnicas utilizadas por los periodistas literarios contemporáneos siguen priorizando el contacto personal y la entrevista en profundidad.

Palabras clave: Periodismo. Literatura. Narrativa. Historico. Metodología.

\section{INTRODUÇÃO}

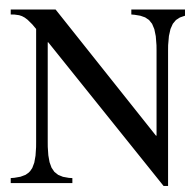

os anos 1960 e 1970 diversos autores estadunidenses passaram a quebrar as normas jornalísticas que predominavam nas redações dos veículos impressos para utilizar recursos da literatura e da ficção em suas reportagens. Esses jornalistas passaram a praticar um estilo que ficou conhecido como New Journalism. Até hoje os autores desse período influenciam aqueles que se aventuram pelas possibilidades do jornalismo literário.

Após autores como Truman Capote, Gay Talese e Hunter Thompson publicarem textos sobre variados temas nos principais jornais e revistas americanos, em 1973, Tom Wolfe publicou um manifesto assumindo a nomenclatura do estilo como New Journalism. Wolfe (2005) explica que o estilo tinha como ambição desbancar o romance de ficção como gênero mais importante da literatura americana. O autor do manifesto destaca que o New Journalism surgiu "causando pânico, tirando do romance o trono de gênero literário número um, inaugurando a primeira novidade da literatura americana em meio século" (WOLFE, 2005, p.9).

Isso quer dizer que o New Journalism tinha objetivos mais voltados para a literatura do que para o jornalismo propriamente dito. Buscava-se transformar esse tipo de jornalismo em algo que também pudesse ser considerado literatura. Mais de quatro décadas depois, o jornalista e pesquisador Robert Boynton, coordenador do curso de Pós-Graduação em Jornalismo Literário da New York University, realizou uma série de entrevistas com jornalistas literários contemporâneos buscando revelar os métodos e técnicas que prevalecem na atualidade. Assim, Boynton publicou The new new journalism (2005). A ideia central é tratar o jornalismo literário como um profissional autônomo, produzindo textos em que os jornalistas utilizam recursos da literatura e da ficção com o intuito principal de fazer jornalismo. $\mathrm{O}$ autor defende que o jornalismo literário tenha metodologias próprias. $\mathrm{O}$ trabalho jornalístico voltado para si mesmo, tendo nele mesmo o seu fim, e não tentando se

Comun. \& Inf., Goiânia, GO, v. 21, n. 1, p. 20-36, jan./mai. 2018 
tornar literatura ou buscando o reconhecimento pelo caráter literário. Para o autor: "Ao contrário dos novos jornalistas, essa nova geração experimenta mais os caminhos de se chegar à história" (BOYNTON, 2005, p.8).

Feita essa breve consideração, o presente artigo busca responder a seguinte questão norteadora: quais são os métodos e técnicas utilizados pelos jornalistas norte-americanos contemporâneos, entrevistador por Boynton? Para tanto, objetiva-se identificar as principais técnicas e métodos utilizados nesse início de século XXI, fazendo reflexões sobre como era a produção no período em que surgiram os integrantes do New Journalism, considerando as diversas mudanças que houveram nessas quase cinco décadas que separam as duas geraões. Dessa forma, inicialmente é feita uma contextualização histórica relembrando o que foi o New Journalism e suas características. Posteriormente são abordados os conceitos de ficção narrativa e da narrativa no jornalismo. Por fim é apresentada a pesquisa de Boynton (2005) com algumas análises prévias, com o objetivo de contribuir para as discussões sobre o assunto. Vale acrescentar que o presente artigo se justifica justamente pela influência que a produção jornalístico-literária americana sempre teve na produção, não só brasileira, mas da América Latina como um todo. Dessa maneira, é apresentada aqui a hipótese de que, mais uma vez, a geração contemporânea de jornalistas literários americanos se ainda não está, irá, em um futuro breve, influenciar as produções brasileiras nessa área.

Metodologicamente, o presente artigo caracteriza-se como uma pesquisa exploratória, desenvolvida com base na pesquisa qualitativa (MINAYO, 1994). As pesquisas exploratórias têm como principal finalidade desenvolver, esclarecer e modificar conceitos e ideias, visando à formulação de problemas mais precisos ou hipóteses para estudos posteriores. Nesse sentido, optou-se pela pesquisa bibliográfica, que é pertinente "se o desejo é formular e encontrar respostas em fontes bibliográficas do campo da educação e outros campos do saber" (TEIXEIRA, 2005, p.118).

Também optou-se pela visão metodológica de Feyerabend (2003). O filósofo ressalta que nenhum processo metodológico deve ser ignorado durante a realização da pesquisa. A definição prévia de uma metodologia fechada pode privar o estudo de chegar a pontos importantes sobre o tema abordado. Feyerabend (2003) defende que se utilizem as ferramentas necessárias de diferentes metodologias para se buscar respostas aos problemas norteadores de uma pesquisa.

Juremir Machado da Silva, por sua vez, propõe que o pesquisador faça um trabalho semelhante ao do cronista, no sentido de levantar o véu do cotidiano, "trazendo à tona aquilo que 
estava escondido pelo excesso de familiaridade" (SILVA, 2011, p. 14-15). Nesse sentido, em relação ao estilo adotado no decorrer da pesquisa, optou-se por um modelo próximo da proposta de crônica de Silva (2011) e da proposta ensaística de Adorno (2003), apresentada no texto Ensaio como forma. Nele, o autor apresenta uma crítica à ideia de que um texto ensaístico geralmente é excluído do campo acadêmico, pois ele evoca uma liberdade de espírito. "O ensaio reflete o que é amado e odiado, em vez de conceber o espírito como uma criação a partir do nada, segundo o modelo de uma irrestrita moral do trabalho. Felicidade e jogo the são essenciais" (ADORNO, 2003, p. 15). Por meio de um texto com estilo mais ensaístico é possível, a partir da visão de diversos autores, apresentar novas visões, ao invés de simplesmente repetir as perspectivas já conhecidas. Em outras palavras, é um texto que se preocupa mais em analisar o objeto estudado, do que em reproduzir o que já está produzido.

Tal método também evita uma submissão ou uma subalternidade do pesquisador em relação aos autores pesquisados nesse estudo. Ou seja, procura-se, aqui, apresentar mais uma extensão das obras de forma interpretativa, com caráter autoral, em substituição a um texto onde repetimos o que já foi dito de forma subalterna. Em síntese, Adorno (2003) defende uma abordagem onde o ensaio é, em si, a sua própria forma.

Também é partilhada a visão crítica que Adorno (2003) apresenta sobre a falta de segurança que há, atualmente, no meio acadêmico de diversos campos do conhecimento, dentre os quais, a Comunicação. Essa insegurança atua no sentido de ter que justificar através de páginas e mais páginas a importância de determinada pesquisa ou de determinado texto, como se o texto e o objeto desse texto, por si só, não se justificassem. É a tentativa absurda de tentar dizer, por meio de diversos mecanismos que muitas vezes mais silenciam o objeto do que o fazem falar, que algo é importante. Ou seja, Adorno (2003) apresenta a ideia de que o ato de escrever sobre algo é, antes de tudo, o ato do autor colocar em algo objetivo as suas milhões de ideias que, até então, só existiam subjetivamente no âmbito do imaginário. Feitas essas considerações, também vale ressaltar que se optou no presente texto pela tradução livre das citações feitas de obras em língua inglesa e espanhola.

\section{AS ASPIRAÇÕES LITERÁRIAS DO NEW JOURNALISM}

Estados Unidos, anos 1960. John Mularo é um americano pai de família casado com a bela Judith Palmer. Mularo se considera um típico conservador, mas que mantém amantes fora do casamento. Uma delas é Barbara. Apesar dos encontros com Mularo, Barbara se casa com John Williamson, que a introduz a uma comunidade de amor livre. Depois de um longo tempo ser ver

Comun. \& Inf., Goiânia, GO, v. 21, n. 1, p. 20-36, jan./mai. 2018 
Mularo, Barbara volta a contatá-lo e o convida para participar do grupo, ao que ele aceita. Na sua primeira participação na reunião de casais, Mularo considera aquilo o máximo, pois além de ver mulheres nuas passeando pela casa, ele pode possuir a quem bem desejar, desde que a escolhida concorde - e a maioria concorda. E mais: ele as tem com a permissão de seus maridos! E essa passa a ser a rotina de Mularo: vida pacata com mulher e filhos em casa e orgias na casa do casal Williamson. Tudo está bem até que Williamson e Barbara resolvem convidar Judith, esposa de Mularo, para um jantar. Sem saber como explicar para a mulher o que acontecia na casa do amigo, Mularo diz que ouviu no escritório um rumor de que nos jantares dos Williamson as pessoas ficavam nuas e se comportavam estranhamente. Judith achou que era piada e considerou o papo do marido absurdo.

Tomado de receio, Mularo foi ao jantar com a esposa. No entanto, ao ver os donos da casa e os convidados, ele é surpreendido: todos estão vestidos e agindo normalmente. A cerimônia está ocorrendo sem nada de anormal até que Judith comenta o que o marido disse sobre os rumores do escritório. Então, os donos da casa e os convidados confirmam os rumores de que, de fato, as pessoas costumam ficar peladas e fazer sexo entre elas durante os encontros. A partir disso, tudo vem à tona: o caso de Mularo com Barbara, as participações dele nos encontros e outras traições conjugais. Em meio às revelações do marido, Judith também confessa que já o traiu e, então, Mularo propõe à esposa que ambos participem do grupo. Ela aceita, inicialmente contrariada, e na mesma noite vê o marido ir para o quarto com outra mulher. Os gemidos da "outra" se confundem com o choro de Judith, que dá para se ouvir vindos do lado de fora do quarto.

Esse é apenas o início da narrativa sobre uma comunidade de amor livre criada por John Williamson, e contada por Talese (2002) em A mulher do próximo. A obra exemplifica as aspirações literárias dos jornalistas do período, mesmo que a metodologia de apuração fosse totalmente jornalística. Talese não se contentou em entrevistar centenas de pessoas, "algumas delas mais de cinqüenta vezes" (TALESE, 2002, p. 465), e trabalhou levantando dados e pesquisando o assunto durante nove anos, até a publicação do livro.

Assim como os mucrakers fizeram nos Estados Unidos da virada do século XIX para o XX, nos anos 1960 e 1970 jornalistas voltaram a se infiltravam em indústrias disfarçados de trabalhadores e realizavam centenas de entrevistas para revelar escândalos e fazer denúncias sociais. Reese (2010) explica que os muckrakers foram um grupo de jornalistas que se destacaram na imprensa norte-americana a partir de 1890, justamente por fazer investigações e grandes reportagens denunciando quem quer que fosse, desde políticos do alto escalão do

Comun. \& Inf., Goiânia, GO, v. 21, n. 1, p. 20-36, jan./mai. 2018 
governo, até grandes companhias e empresários.

Já em relação aos anos 1960, vale recuperar o momento cultural que era vivido nos Estados Unidos e a relação que essa cultura tinha com o contexto jornalístico do período:

Na década de 1960, os Estados Unidos viviam um efervescente processo de transformação social, comportamental e no plano das artes, cujo movimento maior poderia ser classificado em termos do movimento hippie, ou da contracultura em ebulição que procurava encontrar uma alternativa para os padrões convencionais do American Way of Life. A juventude questionava os valores estabelecidos, experimentava opções ousadas de vida - liberação sexual, comunidades, famílias "tribais" e não-nucleares, drogas, alimentação natural, filosofia e misticismo orientais, rejeição do serviço militar obrigatório [...] (LIMA, 2009, p. 121-122)

Isso tudo influenciou essa geração de jornalistas. Assim como os jovens questionavam a cultura estadunidense, os jornalistas literários passaram a questionar a superficialidade com que as notícias eram tratadas pelos jornais. A falta de profundidade e de atração estético-literária dos textos do jornalismo da época irritava jornalistas como Wolfe. Em seu manifesto, o jornalista salienta que não queria contar parte da história que envolvia determinados acontecimentos, mas sim, a história completa: "Eu queria o filme inteiro, sem deixar nada de fora" (WOLFE, 2005, p.10).

A partir disso, Wolfe buscou o que a maioria dos repórteres do jornalismo norteamericano da época procuravam: "simplesmente ser estrelas! E tão apagadinhas!" (WOLFE, 2005, p.12). Recém ingresso no mundo do jornalismo cotidiano, Wolfe se deparou com dois tipos básicos de jornalistas: aqueles que corriam para ter o furo jornalístico e os que queriam ser escritores de matérias especiais. Eles buscavam um triunfo final, que seria produzir uma matéria que fosse algo comparável a um romance.

Como ressalta Wolfe, para se entender o New Journalism na contemporaneidade é preciso assimilar o que o ato de escrever um romance representava para qualquer candidato a escritor: "O romance não era uma mera forma literária. Era um fenômeno psicológico. Era uma febre cortical. Fazia parte do glossário da Introdução geral à psicanálise, em algum ponto entre narcisismo e neurose obsessiva" (WOLFE, 2005, p.16).

Em relação à historicidade do estilo, Bulhões (2007) aponta alguns marcos pontuais na história do New Journalism - lembrando que o estilo já existia antes, através de jornalistas como Joseph Mitchel e Joan Didion, no entanto, ainda não havia essa denominação. O primeiro marco é em 1962, quando Talese publica, na revista Esquire, uma reportagem-perfil sobre o ex-boxeador Joe Louis, que marcaria essa nova tendência, por apresentar sinais claros das transformações que 
estavam chegando. "Talese constrói seu texto apoiando-se largamente em diálogos intimistas como o entabulado entre Louis e sua esposa - manejando com habilidade um atraente jogo narrativo-expositivo" (BULHÕES, 2007, p. 147).

Um ano depois é a vez de Jimmy Breslin adotar o mesmo estilo em sua coluna do jornal Herald Tribune. Em seguida, aparece Tom Wolfe:

$\mathrm{O}$ atrevimento de Wolfe vinha com transgressões mais cortantes, tanto no manejo das técnicas de captação jornalística, quanto no plano da expressão verbal, com a presença extravagante de travessões, pontos de interrogação, reticências, uso multiplicado de letras para produzir um efeito gráfico e fônico e mudanças constantes de foco narrativo, em que o narrador entra na cabeça de seus personagens, assumindo sua perspectiva e as marcas da sua linguagem (BULHÕES, 2007, p. 147).

Um marco nessa trajetória foi a publicação de uma carta escrita por Wolfe ao editor da revista Esquire, Byron Dobell, em 1964, que a transformou em matéria. O episódio é lembrado por Wolfe (2009, p. 44) em entrevista cedida para Revista Magis:

Escrevi a reportagem The kandy-kolored tangerine-flake streamline baby das 6 da tarde às 6 da manhã do dia seguinte. Escrevi 48 páginas naquela noite. Tenho de confessar que, quando eu já estava com meio caminho andado, comecei a me dizer "Hei, esta metade não está mal". Então, não me surpreendi quando o editor, Byron Dobell, me acordou naquela tarde com um telefonema me informando que eles tinham a intenção de tirar o "Caro Byron" das minhas anotações e publicá-las da forma como estavam. Aquela história tinha a vantagem do tom solto e confuso que vem naturalmente, quando você está escrevendo uma carta para uma pessoa, nesse caso, o caro Byron.

No entanto, esse tipo de texto passou a ser utilizado em jornais e revistas, ainda não havia uma denominação específica, como ressalta Wolfe, apresentando uma versão para uma possível origem do termo:

Seymour Krim me conta que ouviu essa expressão ser usada pela primeira vez em 1965, quando era editor do Nugget e Pete Hamill o chamou para dizer que queria um artigo chamado "O Novo Jornalismo" sobre pessoas como Jimmy Breslin e Gay Telese. Foi no final de 1966 que se começou a ouvir as pessoas falarem de "Novo Jornalismo" em conversa, pelo que posso lembrar (WOLFE, 2005, p. 40).

Nesse cenário aparece a figura de um importante escritor-jornalista que consagrou o gênero: Truman Capote. Com a publicação de $A$ sangue frio ele influenciou as futuras gerações de escritores-jornalistas. Conforme Bulhões (2007), Capote considerava que desde a década de 1920 nada de inovador havia sido registrado na literatura, e apostou, assim, que a prática e as técnicas do jornalismo poderiam levar o seu texto a uma inovação. $\mathrm{O}$ escritor queria "escrever uma longa

Comun. \& Inf., Goiânia, GO, v. 21, n. 1, p. 20-36, jan./mai. 2018 
narrativa apoiada na prática jornalística, uma narrativa sem fabulação, sem formulação imaginativa, um romance jornalístico, se isso faz algum sentido" (BULHÕES, 2007, p. 149). E conseguiu, conforme ressalta Chillón:

Capote harmoniza sabiamente todos os ingredientes que fazem uma boa novela realista: a caracterização minuciosa, poliédrica, dos personagens principais; a complexa arquitetura composta no relato, na qual estão incorporadas as cenas, com a utilização dos resumos narrativos, dos diálogos, das tipografias, cartas, declarações, retratos, as elipses e digressões informativas, o uso de detalhe realista, utilizado como um recurso local para condensar uma psicologia ou uma situação, e, especialmente, a habilidade de contar a história, que repousa em grande parte na voz de um narrador onisciente com uma impessoalidade flaubertiana (CHILLÓN, 1993, p.118).

Como se estivesse criando um enredo de um romance, Capote (2003) apresentou detalhes da vida de dois criminosos que chacinaram uma família em Holcomb, no estado do Kansas, além de descrever as vítimas e outros personagens envolvidos.

Foi assim que os jornalistas-escritores transformaram o jornalismo na melhor literatura produzida nos anos 1960 e 1970.

\subsection{Os recursos do New Journalism}

Para o presente estudo é válido ressaltar algumas das características que demarcaram o New Journalism. A primeira delas é o tamanho das reportagens. Wolfe conta que a média dos textos atingiam no máximo 1500 palavras, mas com o aparecimento do novo estilo esses textos passaram a ter mais de 3 mil palavras, às vezes ultrapassando as 6 mil. O espaço utilizado para a prática desse novo estilo foram os suplementos da edição de domingo dos jornais.

Uma das técnicas narrativas utilizadas por Wolfe (2005) era começar a história deixando o leitor, através do narrador, falar com os personagens, incitando uma interação, no sentido de que o leitor os intimidasse, os xingasse, os provocasse. Ou seja, era um texto que buscava tirar o leitor da sua zona de conforto. Essa também é uma das técnicas utilizadas por ficcionistas, apontada na sistematização apresentada por Lodge (2011).

Outro recurso do New Journalism é o autor falar sobre ele mesmo, biograficamente, porém, em terceira pessoa: "Uma vez, até comecei uma história sobre um vício para o qual tinha certa tendência, roupas feitas sob medida, como se outra pessoa fosse o narrador intimidante" (WOLFE, 2005, p.31).

Além disso, para a prática do New Journalism era necessário ter muito mais do que 
técnica: era preciso ter personalidade.

Quando chegavam àquele tom bege pálido, isso inconsciente os alertava [os leitores] de que ali estava de novo aquele chato bem conhecido, o jornalista, a cabeça prosaica, o espírito fleumático, a personalidade apagada, e não havia como se livrar do pálido anãozinho, senão parando de ler. Isso nada tinha a ver com objetividade e subjetividade, ou com assumir uma posição de compromisso - era uma questão de personalidade, de energia, de tendência, de bravura... numa palavra, de estilo... A voz-padrão do autor de não-ficção era como a voz padrão do locutor... arrastada, monótona (WOLFE, 2005, p. 32).

Wolfe (2005) deixou em seu texto quatro recursos básicos para a prática do New Journalism. O primeiro é a necessidade de se contar a história cena a cena, ou seja, passando o enredo de cena para cena sem recorrer tanto à narrativa histórica. Para isso, o autor destaca que é necessário desenvolver o segundo recurso básico: o registro dos diálogos completos, pois, "o diálogo realista envolve o leitor mais completamente do que qualquer outro recurso" (WOLFE, 2005, p.54). Esse recurso foi um dos que mais causaram polêmica, no debate que existia com os romancistas da época, pois, enquanto os ficcionistas optavam pela redução ou eliminação de diálogos completos, os jornalistas adotavam isso como um dos pilares do novo estilo.

O terceiro recurso é o ponto de vista da terceira pessoa, apresentando cada cena ao leitor por intermédio de um personagem. Segundo Wolfe, isso dava "ao leitor a sensação de estar dentro da cabeça do personagem, experimentando a realidade emocional da cena como o personagem experimenta" (WOLFE, 2005, p.54).

O último recurso citado por Wolfe (2005) é o registro de gestos, hábitos, maneiras, costumes, estilos, roupas, decorações, maneiras de viajar, comer, manter a casa, modo de se comportar com os filhos, com os criados, com os superiores, com os inferiores, com os pares, além de olhares, poses ou qualquer outro elemento simbólico do cotidiano que possa existir dentro da cena narrada. A observação e a descrição como elemento central da narrativa.

\section{AS NARRATIVAS LITERÁRIAS E JORNALÍSTICAS}

Nessa breve conceituação, optou-se por destacar as premissas de Genette (1995) sobre a narrativa. Ele destaca que a narrativa apenas pode acontecer através de um discurso discurso narrativo. Metodologicamente, o autor sugere interações envolvendo a narrativa, a história e a narração, além de considerar tempo (história do discurso), modo (tipo de discurso) e voz (narrador). 
Pode-se apontar aqui, como marco inicial do pensamento sobre essas questões, a relação entre história e literatura feita pelo filósofo Aristóteles (384 a.C. - 322 a.C.), ainda na Grécia Antiga. Como destaca Hohlfeldt, Martino e França (2002, p. 75): “Aristóteles é, pois, o primeiro a refletir a respeito das diferentes artes e dos gêneros artísticos, temas que, depois, ocupariam a Estética ao longo dos séculos".

Em A Poética Aristóteles faz essa relação pela primeira vez, salientando a diferença entre o trabalho do historiador e o do poeta - neste último, o escritor não conta o que aconteceu, mas aquilo que é possível, conforme a verossimilhança e a necessidade, enquanto o historiador buscaria o fato real. Pode-se fazer essa mesma comparação com o que ocorre na relação entre a literatura e o jornalismo contemporâneo, pois, como destaca o filósofo grego:

O historiador e o poeta não diferem pelo facto de um escrever em prosa e o outro em verso (se tivéssemos posto em verso a obra de Heródoto, com verso ou sem verso ela não perderia absolutamente nada o seu caráter de história). Diferem é pelo fato de um relatar o que aconteceu e o outro o que poderia acontecer. Portanto, a poesia é mais filosófica e tem um caráter mais elevado do que a História. É que a poesia expressa o universal, a História o particular (ARISTÓTELES, 1999, p. 54).

Assim como a literatura contemporânea preocupa-se mais com o universal, o jornalismo, como a história da Grécia Antiga, trabalha mais o particular. Conforme Aristóteles "o universal é aquilo que certa pessoa dirá ou fará, de acordo com a verossimilhança ou a necessidade, e é isso que a poesia procura representar" (ARISTÓTELES, 1999, p.54), enquanto o particular seria o que aconteceu. Seguindo o pensamento aristotélico, acrescente-se que o poeta da Grécia Antiga, bem como o ficcionista, constrói um enredo que imita as ações e as emoções. O filósofo acrescenta que nada impede de serem abordados fatos reais na poesia, ou no caso da contemporaneidade, nos romances ficcionais: "E, se lhe acontece escrever sobre fatos reais, não é menos poeta por isso: nada impede que alguns fatos que realmente aconteceram sejam [possíveis e] verossímeis e é nessa medida que ele é o seu poeta" (ARISTÓTELES, 1999, p. 55). Ou seja, nada impede que o autor ou escritor utilize fatos reais em enredos de ficção.

Em termos de ficção narrativa, Reis (2003) enumera os seguintes elementos fundamentais da estrutura narrativa:

1) os textos narrativos traduzem uma atitude de exteriorização, centrada num narrador que conta a história; 2) em função dessa atitude, os textos narrativos implicam uma representação de tendência objetiva; 3) os textos narrativos contemplam procedimentos que instauram uma dinâmica de sucessividade (REIS, 2003, p. 347). 
Tem-se essa estrutura, com uma exteriorização que se centra em um narrador, que implicam uma representação objetiva e que aparecem de maneira sucessiva. Nesse sentido, essa estrutura, presente na ficção, pode ser apropriada pelo jornalista que, como ressaltou Aristóteles, não anula a utilização do real na narrativa literária. E qual é a função desse narrador? Recorre-se a Benjamin (2012) para responder tal questionamento. Para o autor a narração não está interessada em transmitir o 'puro em si' daquilo que está sendo narrado como uma informação ou um relatório. "Ela mergulha a coisa na vida do narrador para em seguida retirá-la dele. Assim se imprime na narrativa a marca do narrador, como a mão do oleiro na argila do vaso" (BENJAMIN, 2012, p. 205). Feitas essas considerações, parte-se, a seguir, para a análise dos métodos e técnicas utilizados pelos jornalistas literários contemporâneos da atualidade.

\title{
4 OS NOVOS JORNALISTAS LITERÁRIOS
}

Em tempos de internet, com a facilidade de se pesquisar através de sites como o Google.com, reduzindo o espaço existente entre jornalista e fonte, o que mudou da geração do New Journalism para a geração denominada por Boynton (2005) de "novos novos jornalistas"?

É pertinente trazer para a discussão um dos principais nomes do New Journalism, e que está entre os entrevistados por Boynton (2005): Gay Talese. Em uma entrevista concedida a uma rede de televisão brasileira, Talese fez essa reflexão. O jornalista-escritor disse que até hoje não aderiu aos sites de pesquisa, e que continua utilizando os mesmos métodos de escrita e narrativa de quatro décadas atrás.

\begin{abstract}
Alguns dias atrás eu escrevi um artigo para o New York Times, como freelancer. Escrevi sobre visitar Nova York em um barco. Escrevi como eu faria quando tinha 24 anos. Você vai até o lugar, vê as coisas, encontra pessoas. Conheci uma mulher da China. Uma da Alemanha. Uma da Suécia. Um homem de Chicago. O mundo vem até você se você sai e estabelece contato. Mesmo num lugar pequeno, como um barco (TALESE, 2009) ${ }^{2}$.
\end{abstract}

$\mathrm{Na}$ entrevista, ele também comentou que não acredita que "tenha algo que substitua e domine a vida humana", como o Google e outros sites. Em seu livro, Vida de escritor, Talese (2009) publica alguns textos que foram rejeitados por jornais e revistas americanos. Dentre as quais, há uma matéria sobre uma jogadora de futebol chinesa que perdeu um pênalti na final

\footnotetext{
${ }^{2}$ Disponível em: <https://www.youtube.com/watch?v=wJSDNmhoLhE>. Acesso em: 5 maio 2014.
} 
da Copa do Mundo Feminina. Ele conta que escreveu a narrativa da mesma maneira que o faria quando era jovem. Já em palestra ministrada por palestra na New York University em 2013, assistida pelo autor, Talese destacou que se fosse destacado para cobrir uma reportagem por um grande veículo, como o New York Times ou o Washington Post, ele adotaria as mesmas técnicas e metodologias utilizadas quando estava iniciando a sua carreira.

Boynton (2005), por sua vez, ressalta que as novas tecnologias e métodos de apuração não anulam tudo o que foi feito até os anos 1970. O que há de diferente é a ambição do New Journalism, que colocava a literatura em primeiro lugar, enquanto que atualmente os jornalistas que produzem livros-reportagens colocam a questão jornalística em primeiro plano: "Nem romancistas frustrados, nem repórteres rebeldes, eles querem ser escritores de revistas e livros que tem se beneficiado enormemente do legado legítimo que Wolfe e os outros deixaram na literatura de não-ficção”(BOYNTON, 2005, p.6-7).

Sinteticamente, analisando as respostas dos 19 entrevistados por Boynton (2005), o principal ponto comum e é o interesse humano como primeiro critério de escolha da pauta. Assim como destacou Talese em sua entrevista, nada substitui o lado humano e a tentativa de contar a história da maneira mais completa possível.

Para realizar a série de entrevistas, que teve como objetivo contribuir para as metodologias utilizadas pelos profissionais que optam por esse tipo de jornalismo, Boynton (2005) fez dezenas de perguntas aos entrevistados. Essas questões vão desde perguntas simples, como "que horas você levanta e qual o seu horário preferido para escrever?", até outras mais complexas, como "quais são os elementos necessários para se contar uma boa história?"

Cada entrevista levou em consideração as obras produzidas e a biografia do escritor, porém, para a presente análise considerou-se aquelas que dizem respeito à narrativa jornalística e técnicas de produção. Para Ted Comover, autor de Rolling Nowhere (1984), Coyotes (1987) e Newjack (2000), a narrativa em um livro-reportagem deve ter os mesmos elementos de uma boa ficção: "personagens, conflito, mudança de tempo da narrativa. E, se você está realmente abençoado, você consegue uma resolução. Mas a vida geralmente não funciona dessa maneira" (BOYNTON, 2005, p.11). Outro método revelado é o de escrever sobre assuntos que ele não conhece bem, para deixar que a curiosidade do autor pelo tema seja transmitida ao leitor na narrativa. "Todas as experiências que eu antecipo - até torço para acontecer - estão no início. E eu sei que eu tenho que esperar, esperar e esperar... e isso talvez não aconteça" (BOYNTON, 2005, p. 14). 
Richard Ben Cramer, por sua vez, fala sobre os seus métodos de apuração, pois ele é conhecido nos Estados Unidos por contar "histórias impossíveis", muitas delas histórias de guerra e política, entrevistando líderes do mundo inteiro. O vencedor do Prêmio Pulitzer de 1979 revela que tem a preferência por escrever longos perfis.

Eu acredito que escrever sobre um humano é a coisa mais difícil de se fazer. Mas é a mais satisfatória para o leitor porque a maioria das pessoas aprendem mais facilmente com conhecimentos pessoais. Então se eu posso, com efeito, introduzir aos leitores uma pessoa mostrando o seu mundo, isso funciona melhor como um processo orgânico do que, digamos, uma história de John McPhee, que constrói cuidadosamente de maneira impessoal (BOYNTON, 2005, p. 51).

Outro jornalista que reflete sobre a diferença entre a profundidade do jornalismo literário e a do jornalismo praticado em hard news, como as notícias dos sites de minuto a minuto, é Leon Dash. Ele foi vencedor do prêmio Pulitzer ao publicar uma série de reportagens no Washington Post contando o drama da jovem Rosa Lee e sua família na luta contra a pobreza e contra a Aids (que a mataria meses depois da publicação, no mesmo dia em que o jornalista ficou sabendo que ganhou o Pulitzer).

Para Dash, as pessoas têm uma máscara pública, independentemente de serem famosas ou não. E, para desvendar o que há por trás da máscara pública, é necessário dedicar tempo, pesquisa, encontros e entrevistas. "A maioria das histórias que os repórteres pegam - por causa do tempo e da pressão do deadline - raramente ultrapassam essa máscara" (BOYNTON, 2005, p.57). Para isso, Dash revela que nunca entrevista uma pessoa por telefone, e-mail ou carta. "Eu preciso do contato face a face com as pessoas que estou entrevistando" (BOYNTON, 2005, p.63).

William Finnegan, por sua vez, destaca que prioriza a complexidade dos personagens. O autor de Cold new world: gorwing up in a Harder Country, dentre outras obras, conta que esse é o principal motivo pela qual geralmente ele opta por escrever sobre o mundo dos adolescentes. Também por isso ele evita escrever sobre pessoas famosas. "Eu tenho aversão de escrever sobre pessoas que tem assessores. Jornalisticamente, esse já é um campo lotado" (BOYNTON, 2005, p.79). Ele acrescenta que geralmente as celebridades veem os jornalistas como uma peça da máquina publicitária e mercadológica.

Um dos autores entrevistados por Boynton (2005) que conquistou fama internacional por seus livros escritos na contemporaneidade é Jon Krakauer, autor de Into de Wild (1996), publicado em português como Na natureza selvagem. Ele comentou sobre a presença do autor 
na narrativa. Em seu caso, Krakauer diz preferir não ser um personagem das histórias narradas.

Meu instinto é escrever em terceira pessoa, e manter-me fora da história, mas alguns editores de revistas quase sempre pediam para escrever em primeira pessoa. Eles dizem "nós queremos que o leitor veja o que você vê, cheire o que você cheira, sinta exatamente o que você sente enquanto você está captando a história”. Algumas vezes eu gosto de escrever em primeira pessoa porque isso me dá uma riqueza de material para trabalhar (BOYNTON, 2005, p. 179).

Em seu livro Na natureza selvagem o jornalista narra a história de um jovem de classe média alta que abandonou a família, a namorada e os estudos para viver isolado na selva (KRAKAUER, 1998).

Outro autor que fala sobre técnicas narrativas é Ron Rosenbaum, que escreveu Explaining Hitler (1998) e Those who forget the past (2004). Ele salienta que, devido ao trabalho de apuração, entrevistas, transcrições de diálogos, esperas e agendamentos, a elaboração da narrativa de um livro-reportagem pode ser muito mais difícil do que a de uma narrativa ficcional. Rosenbaum contou sobre o como trabalha a narrativa em suas reportagens:

Eu usava transcrições de Cortes, falas das testemunhas, observações da investigação. Mas eu sempre achei que havia, inevitavelmente, um monte de pontos de vista conflitantes que dificultavam a reconstruir uma narrativa verdadeiramente transparente. Então eu comecei a questionar essa técnica. Agora eu posso construir narrativas usando uma série pontos de vista conflitantes e particulares. Isso geralmente surge no ponto da narrativa em que a inevitável questão emerge: porque a história dessas pessoas são conflitantes? (BOYNTON, 2005, p. 334).

A partir dessa questão, Rosenbaum começa a contar as histórias dos personagens utilizando o lead da cena. "Um bom lead incorpora muito do que a história trata - é tom, é foco e é humor" (BOYNTON, 2005, p.334).

Analisando as 19 entrevistas feitas por Boynton (2005), pode-se perceber uma ampla variedade de respostas para cada método ou técnica, tanto no que diz respeito à apuração, às rotinas e à narrativa. Porém, é inegável a relevância de cada resposta para as discussões sobre essa prática jornalística. É válido destacar ainda que esse é uma das primeiras reflexões sobre o tema pensando sob a perspectiva de ter o jornalismo em primeiro plano em livros de nãoficção.

\section{CONSIDERAÇÕES FINAIS}


A utilização de técnicas da ficção narrativa nas grandes reportagens e nos romances de não-ficção, é algo que nasceu com a narrativa jornalística e que não vai ser substituída por tecnologias. Por mais que muitos acreditem na morte do livro, mesmo que as narrativas jornalísticas no formato de grandes reportagens se transfiram para o computador - tese desacreditada nesse estudo - os elementos da ficção continuarão sendo utilizados por jornalistas.

Durante as décadas em que produziu jornalismo literário, Hunter Thompson (19372005) foi um dos jornalistas que melhor trabalhou com a mescla de técnicas da ficção em reportagens nos anos 1960 e 1970. Uma dessas técnicas era a falsa nota do editor. Em determinada parte do texto, ele escrevia uma falsa nota para dar alguma explicação que ele julgava necessária para o leitor entender melhor a narrativa. Conforme salienta o biógrafo do jornalista, McKeen, a utilização de cartas nas reportagens era outra técnica utilizada na narrativa de Thompson. "Ele era muito mais ele mesmo nas cartas do que nos próprios artigos, em que ele estava tentando escrever alguma coisa profissional, alguma coisa que pudesse ser publicada no New York Times" (MCKEEN, 2008, p. 74). Essa técnica frequentemente era adotada por Hunter em seus textos que ficaram conhecidos como gonzo, justamente por fazer a mescla entre jornalismo e literatura da qual era praticamente impossível identificar o que era fato e o que era ficção.

Assim como Hunter Thompson, seus predecessores e os seus contemporâneos do New Journalism, os novos jornalistas literários seguem tentando e experimentando, usando fórmulas consagradas por autores como Truman Capote e Gay Talese, pegando um pouco da técnica de cada escritor-jornalista de décadas atrás, invertendo, inventando e reinventando fórmulas narrativas, mas seguem também buscando realizar jornalismo através de textos longos e reportagens investigativas e de profundidade.

Dessa forma, volta-se a questão que norteou essa pesquisa: quais são os principais métodos e técnicas utilizados pelos jornalistas literários contemporâneos? Conforme visto, há mais semelhanças do que diferenças entre os procedimentos metodológicos utilizados pelos jornalistas literários de agora e os dos anos 1960. O tamanho das reportagens, quando publicadas em livro, seguem extensas. Vários autores seguem utilizando a técnica de se falar com o personagem. Além disso, a personalidade do autor ainda é mais valorizada do que o uso de tecnologias ou a utilização de recursos gráficos. Além disso, o principal ponto: o caráter humano é a grande unanimidade. Não há tecnologia que substitua isso na apuração de uma grande reportagem. Além disso, os entrevistados contemporâneos também concordam

Comun. \& Inf., Goiânia, GO, v. 21, n. 1, p. 20-36, jan./mai. 2018 
que a sua função principal é, antes de mais nada, contar uma boa história. Para isso, as novas tecnologias podem auxiliar, mas não substituir a capacidade do autor em construir uma narrativa atrativa que, geralmente, explora o caráter humano e muitas vezes se vale, ainda, dos quatro recursos citados por Wolfe em seu manifesto: a narração cena a cena, a transcrição de diálogos, o ponto de vista da terceira pessoa e o registro dos hábitos dos personagens e da descrição física e cultural dos lugares.

Nesse sentido, a fala de Talese é esclarecedora, pois ele afirma utilizar os mesmos métodos e técnicas de 50 anos atrás, privilegiando o contato pessoal e conversa face-a-face com as pessoas. Boynton (2005), por sua vez, ressalva que as tecnologias não anulam o que foi feito anteriormente, mas também não são uma solução mágica que vá resolver o problema de candidatos a jornalista-escritor medíocres. Assim, destaca-se que uma narrativa jornalístico-literária geralmente se vale dos mesmos elementos de uma boa ficção, indo ao fundo da complexidade de seus personagens. Conclui-se essa etapa da pesquisa ressaltando que a releitura dos autores ultra citados e a análise dos entrevistados propiciaram que se apresentasse algumas das principais técnicas e metodologias utilizadas pelos jornalistas literários contemporâneos.

Dessa forma, salienta-se a importância da discussão de temas relacionados à técnicas e metodologias utilizadas pelos jornalistas escritores da contemporaneidade, relembrando o que já foi feito pelos autores que consagraram o gênero. Assim, espera-se que o presente artigo possa contribuir para as pesquisas realizadas nessa área de pesquisa, afinal, conforme ressalta Martinez (2009) a pesquisa sobre o jornalismo literário contemporâneo está em processo de construção. Salienta-se, portanto, que essa é uma reflexão inicial sobre a temática que ainda conta com muitos pontos a serem explorados em estudos futuros por este e outros pesquisadores.

\section{REFERÊNCIAS}

ADORNO, T. O ensaio como forma. In: ADORNO, T. Notas de literatura I. São Paulo: Editora 34, 2003. p. 15-45.

ARISTÓTELES. Poética. São Paulo: Nova Cultural, 1999.

BENJAMIN, W. Obras escolhidas: magia e técnica, arte e política. São Paulo: Brasiliense, 2012. v. 1. 
BOYNTON, R. The new new journalism. New York: Random House, 2005.

BULHÕES, M. Jornalismo e literatura em convergência. São Paulo: Ática, 2007.

CAPOTE, T. A sangue frio. São Paulo: Companhia das Letras, 2003.

CHILLÓN, L. Literatura i periodisme: literatura periodística i periodisme literari en el temps de la post-ficció. Alacant: Secretariat de Publicacions de la Universitat d'Alacant; Castelló: Publicacions de la Universitat Jaume I; València: Universitat de València, 1993.

FEYERABEND, P. Contra o método. Rio de Janeiro: Editora Unesp, 2003.

GENETTE, G. Discurso da narrativa. Lisboa: Vega, 1995.

HOHLFELDT, A. MARTINO, L. C; FRANÇA, V. V. (Org.). Teorias da comunicação: conceitos, escolas e tendências. Petrópolis: Vozes, 2002.

JORNALISTAS brasileiros entrevistam Tom Wolfe. Revista Magis, São Leopoldo, n. 4, p. 40-45, out./nov. 2009.

KRAKAUER, J. Na natureza selvagem. São Paulo: Companhia das Letras, 1998.

LIMA, E. P. Páginas ampliadas. Barueri: Manole, 2009.

LODGE, D. A arte da ficção. Porto Alegre: L\&PM, 2011.

McKEEN, W. Outlaw journalist: the life and times of Hunter S. Thompson. New York: W.W. Norton e Company, 2008.

MARTINEZ, M. Jornalismo literário: um gênero em expansão. Revista Intercom. 2009.

Disponível em:

<http://www.portcom.intercom.org.br/revistas/index.php/revistaintercom/article/viewFile/267 /260>. Acesso em 20 de junho de 2014.

MINAYO, M. C. de S. (Org.) Pesquisa social: teoria, método e criatividade. Petrópolis: Vozes, 1994.

REESE, J. The early muckrakers: Nellie BLy, Lincoln Steffens, Upton Sinclair, Ray Stannard Baker, et al. Webster's Digital: New Delhi, 2010.

REIS, C. O conhecimento da literatura: introdução aos estudos literários. Porto Alegre: Edipucrs, 2003.

SILVA, J. M. O que pesquisar quer dizer: como fazer textos acadêmicos sem medo da ABNT e da Capes. Porto Alegre: Sulina, 2011.

TALESE, G. A mulher do próximo. São Paulo: Companhia das Legras, 2002.

TALESE, G. Vida de escritor. São Paulo: Companhia das Letras, 2009.

TALESE, G. Assista à íntegra da entrevista com Gay Talese. 2009. Disponível em: $<$ https://www.youtube.com/watch?v=wJSDNmhoLhE>. Acesso: 5 de maio de 2014.

TEIXEIRA, E. As três metodologias. Petrópolis: Vozes, 2005.

WOLFE, T. Radical chique e o novo jornalismo. São Paulo: Companhia das Letras, 2005. 